\title{
JOHN DEWEY EM VISITA AO JARDIM DE HUXLEY: UMA DISCUSSÃO SOBRE A TEORIA DA EVOLUÇÃO E AS CONCEPÇÕES ÉTICAS
}

\author{
JOHN DEWEY VISITS HUXLEY'S GARDEN: A DISCUSSION ABOUT THE \\ THEORY OF EVOLUTION AND ETHICAL CONCEPTIONS
}

\author{
JOSÉ CLÁUDIO MORELLI MATOS \\ (UDESC-Brasil)
}

\begin{abstract}
RESUMO
John Dewey escreve um de seus primeiros trabalhos sobre ética em resposta às idéias de Thomas Huxley. Huxley, em seu artigo "Evolution and Ethics" (1894), defendia uma oposição entre os processos naturais e os processos éticos. A ética, segundo ele, é contrária aos princípios que se observa na natureza. Para Dewey, por outro lado, não há dualismo entre as regularidades naturais e as regularidades sociais. Dewey pretende, em seu artigo homônimo ao de Huxley (1898), reconstruir o sentido de noções fundamentais ao pensamento evolutivo como "adaptado", "luta pela vida" e "seleção natural". Dando início a uma versão evolucionista da reflexão ética, Dewey supõe a continuidade entre o mundo natural e o mundo dos valores. Suas conclusões indicam não só uma abordagem evolutiva das questões éticas, mas a proposição de valores e condutas que estejam em conformidade com o crescimento e a mudança constante nos ambientes e nas funções adaptativas, tais como se observa no mundo natural.

Palavras-chave: Dewey, Thomas Huxley, Evolução, Ética.
\end{abstract}

\begin{abstract}
John Dewey wrote one of his first works on Ethics in response to Thomas Huxley ideas. Huxley, in his article "Evolution ad Ethics" (1894), argues for an opposition between the natural and the ethic processes. Ethics, according to him, is contrary to the principles observed in nature. For Dewey, on the other hand, there is no dualism between natural and social regularities. Dewey intents, in an homonymous article (1898), rebuild the meaning of fundamental notions in the evolutionary thought such as "fitted", "struggle for life" and "natural selection". Giving start to an evolutionary version of the ethical reflection, Dewey supposes continuity between the natural world and the world of values. His conclusions not just indicate an evolutionary approach to ethical questions, but also the proposal of values and conducts in conformity with growth and constant change of environments and adaptive functions, as observed in the natural world.

Keywords: Dewey, Thomas Huxley, evolution, ethics.
\end{abstract}

\section{INTRODUÇÃO}

Um dos pensadores do século XX que mais manifestamente valoriza a relação simbiótica entre filosofia e ciência é John Dewey. Uma das realizações científicas a que este pensador dava maior atenção é a teoria darwiniana da evolução por seleção natural. Dewey interessava-se pelas 
conseqüências que se podia extrair da obra de Darwin, para o tratamento de temas filosóficos como o conhecimento, a política e a moral. Ele trata deste assunto em diversos textos, dos quais se destaca o já conhecido artigo "The Influence of Darwinism in Philosophy", publicado inicialmente em 1909. Menos mencionado, porém igualmente significativo é seu trabalho de alguns anos antes, intitulado "Evolution and Ethics".

Publicado originalmente no periódico The Monist em 1898, este artigo de Dewey é, em parte, um comentário sobre as idéias acerca do tema, expressas por Thomas H. Huxley, em seu trabalho homônimo de 1893. Além de examinar as teses de Huxley, e de desenvolver seu comentário e críticas acerca delas, Dewey apresenta algumas de suas próprias considerações acerca da relação entre a teoria da evolução e os princípios e reflexões da ética.

Embora se trate de um trabalho relativamente pouco conhecido do público, se comparado a obras como Democracia e Educação (1916) e Experiência e Natureza (1925), pode-se afirmar que este texto de Dewey possui relevância filosófica, pelo menos por duas fortes razões: i) é representativo da posição do autor em relação à relevância da teoria evolutiva de inspiração darwiniana para o empreendimento filosófico, ii) é representativo de idéias que posteriormente, em outras obras, Dewey desenvolve acerca da ética. Um exame mais detalhado deste trabalho proporciona um exercício de algum interesse para quem se volta para a filosofia deste autor, considerado um dos mais produtivos e influentes do pensamento do século XX.

Este artigo mostra Dewey atuando um pouco como comentador de Huxley, citando passagens e esclarecendo elementos de seu discurso. Acerca disso vale recordar o que o filósofo declara acerca de seu contato inicial com o pensamento de Huxley, quando ainda era estudante. Em um texto intitulado "From Absolutism to Experimentalism", em que narra sua biografia intelectual, Dewey afirma ter sido impelido a "desejar um mundo e uma vida que tivesse as mesmas propriedades que tinha o organismo humano em sua imagem derivada do estudo do tratamento de Huxley" (DEWEY, 1981, p. 2). A visão evolutiva da natureza, que incluía o ser humano e suas propriedades, é uma característica que Dewey manifestará em todo o seu pensamento posterior. Como a passagem acima revela, esta visão evolutiva se constitui como uma aspiração, um desejo, nascido do estudo de Huxley.

Mas a conclusão a que Dewey chega é uma marca da originalidade com que trata o tema da evolução: Segundo ele, o processo evolutivo opera no mundo biológico, assim como no mundo cultural e social, produzindo a constante mudança e necessidade de adaptação, por meio 
da comunicação e do pensamento. Não há, para Dewey, dualismo entre as regularidades naturais e as regularidades sociais. Tomando como ponto de partida a atitude naturalista de Dewey, se espera, com esta breve discussão poder mostrar duas coisas:

i) Além de assumir um ponto de vista naturalista em relação aos fundamentos da ética, Dewey assume um ponto de vista naturalista em relação ao próprio empreendimento filosófico, ao manifestar a noção de que ao longo da história das idéias, as controvérsias - via de regra - não são resolvidas unicamente pela argumentação racional, mas pela inadequação ou exaustão das velhas questões, em relação a um ambiente intelectual e social em constante mudança. Segundo ele: "Seria difícil encontrar um único problema ao longo de todo o registro do pensamento reflexivo que tenha sido perseguido consistentemente até que algum resultado definitivo fosse atingido" (DEWEY, 1972, p. 34).

Os valores e hábitos constituintes da conduta moral seguem princípios semelhantes aos que atuam sobre as espécies, e a própria investigação fillosófica e científica segue princípios semelhantes. Para Dewey, a própria disseminação do darwinismo e a postulação da questão concernente à evolução e à ética são casos da seleção de variações mais adaptadas às mudanças ambientais que vão se manifestando. Também pode ser assim entendido o sucessivo aparecimento de novos valores, costumes e distinções morais, sobre valores, costumes e distinções mais antigos.

ii) O tratamento dado por Dewey ao tema da moralidade, à luz da teoria da evolução, é mais complexo e mais sofisticado conceitualmente que o de Huxley. Este último, além de possuir uma prosa elegante e bem argumentada, expressa seu ponto de maneira coerente e bem argumentada. Mas Huxley fecha o caminho para uma consideração naturalista da ética ao propor que a moralidade consiste na oposição aos princípios e regularidades naturais. Este dualismo é que levou muito leitores a suporem que Huxley, com a argumentação aqui discutida, "tinha desistido da sua crença na unidade dos processos evolutivos, aceitando própria idéia dualista da separação entre o animal e o humano" (DEWEY, 1972, p. 35). O que se vê é Dewey estender conceitos evolutivos ao tratamento da moralidade, procurando, com relativo sucesso, escapar ao determinismo e ao cinismo moral a que interpretações mais ingênuas do darwinismo poderiam levar. Dewey raciocina no sentido de propor um tratamento da ética compatível com a atitude naturalista, afirmando não haver oposição ou contrariedade entre a natureza (e o processo evolutivo que nela se observa) e a esfera ética (manifesta nos valores observados nas sociedades 
humanas).

O argumento de Dewey baseia-se num exame dos termos "adaptação", "luta pela vida" e "seleção natural", e do que está implicado em dizer, por exemplo, que um indivíduo, ou uma população, estão adaptados ao ambiente onde se encontram, ou que determinado hábito é mantido porque foi selecionado. Ele pretende mostrar que a oposição entre evolução e ética só se sustenta a partir de uma concepção demasiado estreita do que significa estar adaptado. E, além disso, que os valores morais são legítimos mecanismos adaptativos. As preocupações de ordem ética são adaptações relativamente bem sucedidas que os indivíduos desenvolvem e incorporam, de modo a prosperarem no ambiente complexo que é a sociedade humana. Em suas palavras: "O que quer que seja necessário para a vida nós podemos razoavelmente assumir que tem alguma relevância para a vida moral" (DEWEY, 1972, p. 43). Assim, a forma distinta que os valores tomam em diferentes culturas, diferentes épocas e diferentes condições de vida, representam a busca por maior adaptação entre os organismos e seus respectivos ambientes. Isto conduz Dewey a uma postura compatível com o horizonte darwiniano, no tocante à forma de caracterizar o processo ético, e as variadas condutas e valores assumidos ao longo de tal processo.

\section{OPOSIÇÃO OU CONTINUIDADE}

Dewey inicia sua discussão afirmando que as controvérsias filosóficas cessam por exaustão das alternativas e argumentos, mais do que pela estrita refutação de uma das alternativas. A exaustão de antigos hábitos de pensamento, e sua reconstrução em formas mais adaptadas aos dilemas e necessidades do ambiente teórico atual, é um processo marcado por visível variação. Esta variação se manifesta, por exemplo, na própria mudança da relação entre os conceitos de evolução e ética.

Tal visão acerca das mudanças conceituais reflete a aplicação, por parte de Dewey, de certa versão do chamado "princípio de continuidade", segundo o qual a vida se caracteriza pela contínua renovação e contínua transformação, numa incessante interação entre o organismo e o meio ambiente. Diferentes versões deste princípio são cruciais na compreensão de muitas das discussões de Dewey em diversas outras temáticas como política, educação, estética e teoria do conhecimento. Segundo o autor: "O desenvolvimento da biologia, com sua descoberta da evolução confirma esta lição. Pois a significação filosófica da doutrina da evolução reside 
principalmente em pôr em relevo a continuidade das formas orgânicas mais simples e mais complexas até chegar-se ao homem" (DEWEY, 1959, p. 370).

Do mesmo modo ocorre na sociedade: a vida de uma sociedade é justamente o processo de renovação, primeiro dos indivíduos vivos que a integram, e segundo dos modos de agir e pensar, que a definem como tal. A afirmação de que tanto a vida biológica quanto a vida social estão submetidas à mesma regularidade, ao mesmo mecanismo de renovação sem o qual cessariam de existir, é uma das formulações deste fundamental princípio da continuidade, na filosofia de Dewey.

Estas conclusões do filósofo, numa época de sua vida intelectual em que os temas da evolução e do darwinismo faziam parte de suas preocupações mais expressas, encontram eco em toda a sua obra. Estes podem ser encontrados, por exemplo, em sua consideração ambiental da condição humana, em sua visão do processo democrático como condição para o crescimento e continuidade da vida, e em sua ênfase na experiência como um processo de constante reconstrução.

Um dos mais notáveis exemplos deste princípio é o próprio caso da controvérsia acerca da evolução onde temos, segundo Dewey, a situação seguinte: "Uma geração atrás" - a questão central era da situação do ser humano em relação aos outros animais. Atualmente - a questão da relação entre processos evolutivos e questões éticas. Dewey menciona Huxley e a sua "Romanes Lecture" como o iniciador da discussão, e destaca o impacto causado pela distinção que marca o argumento de Huxley, entre processos éticos e processos cósmicos. Huxley descreve o processo cósmico, apontando para uma ordem, ou regularidade, que pode ser inferida no mundo natural, e que está por trás das inúmeras e incessantes transformações que se observa neste mundo. Segundo suas palavras:

\footnotetext{
O que dura não é uma ou outra associação de formas vivas, mas o processo do qual o cosmos é o produto, e do qual aquelas estão entre as expressões transitórias. E no mundo vivo, um dos traços mais característicos do processo cósmico é a luta pela existência, a competição de cada um com todos, cujo resultado é a seleção, isto é, a sobrevivência daquelas formas que, na totalidade, são melhor adaptadas às condições que se apresentam em qualquer período; e que são, portanto, a este respeito, e apenas a este respeito, as mais adaptadas (HUXLEY, 1895, p. 4).
}

Dewey segue Huxley na suposição de que é possível falar de um processo cósmico, que regula o funcionamento do mundo vivo em geral, e de um processo ético, que regula os valores adotados ethic@-Florianópolis v.9, n.2 p.199-216 Dez.2010. 
nas escolhas e na conduta consciente dos agentes humanos. Entretanto, defende a idéia de que o processo ético não é contrário ao processo de evolução por meio da "seleção do mais adaptado". Neste ponto fundamental ele opõe-se a Huxley que defende que, uma vez que a espécie humana tenha desenvolvido - por meio da evolução de sua vida social - um sistema de valores morais, este processo (o processo ético) segue um curso que é contrário ao curso do sistema da natureza (ou processo cósmico). A divergência entre ambos neste ponto reflete a divergência quanto ao modo de considerar a influência das idéias darwinianas de adaptação e luta pela vida, quando transpostas para assuntos referentes ao mundo humano.

Dewey entende que, de fato, Huxley não abdica de sua posição evolucionista: o processo ético é parte, e resultado do processo cósmico, embora sua manifestação seja opositiva e restritiva do processo originário. Huxley faz uso da conhecida analogia com o cultivo de um jardim. A condução do processo ético seria análoga a demarcar, preparar e cultivar um jardim: O pedaço de solo com plantas e animais crescendo livremente, representa o processo cósmico. O pedaço de solo tratado, cercado e cultivado segundo o plano e a intervenção humana representa o processo ético.

Dewey sugere que a mesma alegoria pode levar a outra conclusão. O homem não opõe o processo ético contra o cósmico, ele apenas ajusta parte do ambiente a suas necessidades. Os elementos envolvidos são mudados de lugar, mas todo o artifício é feito de partes naturais de diferentes ambientes. Esta visão da ambientalidade do processo ético, e de que todo o processo resulta de elementos do mundo natural é originalmente Deweyana. Huxley não tinha elevado seu argumento a este nível de complexidade. Para Dewey, o processo ético é conectivo de elementos provenientes de algumas partes do mundo natural com elementos de outras partes: é, portanto, um refinamento, uma adaptação das condições sociais que tem como ocnsequência o desenvolvimento da esfera ética, na direção de ainda maior adaptabilidade.

\section{ADAPTAÇÃO E LUTA PELA VIDA}

Desta possibilidade de ver a alegoria do jardim sem supor oposição ente o processo ético e o cósmico Dewey conclui a necessidade de atribuir um outro significado ao termo "adaptado". Adaptado é sempre adaptado a certo ambiente. O ambiente, como é fácil observar, evoluiu de modo a incluir o ambiente social. Por isso, a conduta moral é ela mesma adaptativa. Isto pode ser 
aceito sem qualquer contradição como aquela que é enfatizada por Huxley. Ele parece, por sua insistência na dualidade entre natureza e ética, pertencer à "geração anterior", à qual Dewey se refere no início de seu artigo. Para Huxley, não era possível imaginar as idéias, os hábitos, as formas de conduta como mecanismos adaptativos submetidos, eles mesmos, a um processo de evolução mediante a seleção dos mais adaptados. O planejamento e a intenção conscientes, a conduta manifesta em forma de linguagem e comunicação visando o bem comum, não pareciam a Huxley fazer sentido senão como cultivos, artifícios, que fossem restrições, oposições ao processo cósmico.

Dewey propõe tomar o termo "adaptado" em um sentido que permite mostrar que as condutas de cuidar e proteger os interesses dos incapazes e dependentes - que poderiam ser considerados os "fracos" a serem eliminados pelo processo cósmico na visão de Huxley possuem um aspecto adaptativo diante da totalidade de condições do meio social. Estas condutas resultam da adoção de uma perspectiva ética, e operam desenvolvendo planejamento, comunicação e previsão de eventos e regularidades a que as sociedades estão sujeitas. Enquanto Huxley guarda um sentido de "adaptado" que se refere a um ambiente natural que não existe mais, Dewey supõe que diante de mudanças evolutivas o novo ambiente continua submetido ao mesmo tipo de princípio geral. Dewey acabaria por se revelar, por assim dizer, um darwinista mais aferrado que Huxley, pois explora o sentido da seleção do mais adaptado como eficaz princípio explicativo de realizações humanas como a moral e a cultura.

Adaptação não significa, para Dewey, apenas responder de modo adequado a uma mudança ocorrida, mas também prever ou antecipar uma mudança, e desenvolver uma conduta correspondente. Esta adaptação é resultado de comportamento comunicativo e reflexivo, de aprendizagem e deliberação, e de cooperação e compreensão da conduta dos outros. Estar adaptado ao ambiente atual é possuir a plasticidade necessária para aprimorar e transmitir sua herança cultural em um ambiente progressivamente modificável.

Assim como "adaptado", Dewey também pretende reformular o sentido de "luta pela existência", como algo que é regulado pelo ambiente em que o indivíduo se situa. Dewey é enfático ao defender que a luta pela vida não é substituída, na vida humana, por nenhum processo de natureza distinta ou oposta. Para Huxley a luta pela existência possui dois significados:

- Auto-asserção: O indivíduo adota condutas que favorecem sua perpetuação e bem estar. Para Dewey a vida social e eticamente defensável nunca deixa de ser um processo auto-assertivo: 
a vida tende a manter-se pelos meios de que dispõe para isso.

- Um processo egoísta e impiedoso, que manifesta os instintos predatórios da natureza animal. Sobre isso Dewey observa que os impulsos e disposições que valiam no ambiente primitivo são ancestrais de condutas sucessivamente mais complexas e relevantes para o processo ético no ambiente social.

Dewey exemplifica seu ponto quanto à luta pela existência mencionando virtudes como a castidade, a temperança e a benevolência. Estas são exemplos de controle da conduta do sujeito a fim de obter um fim proposto. Há um sentido de luta no conflito entre hábitos que resistem à mudança, e situações que demandam novos hábitos. Dewey vê as virtudes morais como modos de auto-asserção que são mais elaborados e complexos, por se situarem na relação social. Mas afinal elas se originam de um impulso para a vida que remonta aos instintos da natureza animal. Ele afirma ainda que "os assim chamados instintos e prontidões animais herdados não são apenas o estímulo, mas também os materiais da conduta moral” (DEWEY, 1972, p. 45). Os valores atualmente em apreço são adaptações do esforço feito pelos agentes que "devem agora estar adaptados a outras condições" (DEWEY, 1972, p. 45). Em todo o caso, há uma continuidade, um desenvolvimento cumulativo cuja origem é o instinto, e o resultado até aqui é o processo ético.

Em nenhum caso Dewey concede que o processo ético faça sentido como uma negação ou restrição consciente da auto-asserção que, inicialmente, caracterizava o instinto. Por isso, para ele, existe continuidade - e não ruptura ou oposição - entre o processo cósmico e o processo ético. Outra distinção empregada por Huxley é entre "luta pela vida" e "luta pela felicidade". A primeira não podendo existir no processo ético, por envolver a auto-asserção em detrimento da vida do outro, a segunda correspondendo a valores e a objetivos, como parte do processo ético. Dewey declara que não há problema em ignorar esta distinção, já que ela contém uma contradição.

Nas sociedades civilizadas a luta pela existência teria sido substituída pela luta pela felicidade. O processo ético substituiria o processo cósmico e onde aquele opera, não poderíamos mais encontrar este, pois ambos são inconciliáveis, na visão de Huxley. O desafio de Dewey a Huxley neste ponto mostra o que ele considera uma contradição interna ao pensamento deste último: se a luta pela existência chegou ao fim, por que Huxley emprega suas energias em refutála em combatê-la? Por que se preocupar com ela se, afinal, o processo ético substitui o processo cósmico nas sociedades civilizadas? 
Luta pela felicidade e luta pela existência não são excludentes, a distinção não se sustenta. O que se poderia chamar de auto-restrição tem a ver com os modos particulares assumidos pela auto-asserção. "Cuidado, vigilância, constante interferência nas condições tais como elas são, são necessários para manter a ordem ética, como o são para manter o jardim” (DEWEY, 1972, p. 37). A luta se encaixa onde? Não pode ser luta entre o processo cósmico e o ético, porque os materiais de ambos são os mesmos: os impulsos e disposições naturais que evoluem para condutas e hábitos sociais. A luta deve ser para reconstituir e readaptar estes impulsos e funções da conduta a novas condições existentes, de modo que continuem a cumprir sua função. Não se pode inferir por nenhum argumento válido as condições de um estado futuro, um ápice, um cume para o processo evolutivo. Ao invés disso todas as coisas vivas caminham por tentativa e erro na busca constante de estar adaptados às condições que encontram. Mas a eticidade é concordante com as forças e princípios naturais, e não seu oposto.

\section{SELEÇÃO NATURAL E ÉTICA}

Quanto ao sentido de "seleção natural”, para Huxley, ou ela cessou ou continua agindo no mundo social, mas deve ser substituída pela moral, pois a seleção seria eticamente perversa. Em que sentido este termo "seleção natural" pode ser empregado para que se possa determinar se ela ainda opera, e de que modo? A seleção natural é diferente da seleção social? Seria possível afirmar que a seleção cessou, somente se compreendermos este termo no sentido estrito da seleção pela reprodução diferencial e extinção de alguns organismos portadores de certas variações. Mas Dewey pretende estender o termo "seleção" também às formas de conduta, e por isso justificar que ainda no processo ético operam processos de seleção das variações mais adaptadas. Dewey argumenta que hábitos, como funções definidas de conduta, são entidades passíveis de ser submetidas à seleção natural.

Esta seleção é mesmo um processo de seleção natural, não somente social? Natural sim, diria Dewey, e aqui ele marca a sua posição a favor de uma ética naturalista. A educação, as instituições e as formas de conduta social são funções da vida, e como tal, emergem como efeitos dos mesmos princípios naturais que operam na seleção orgânica em sua versão mais literal. A seleção de hábitos na cultura é uma forma da natureza desenvolver modos ainda mais econômicos e eficazes de seleção, sem ter que esperar o tempo necessário para a variação 
biológica se manifestar no transcurso de gerações. Segundo o autor:

\begin{abstract}
Não apenas uma forma de vida é selecionada às expensas de outras formas, mas um modo de ação no mesmo indivíduo é constantemente selecionado às expensas de outros. Não há apenas a triagem pela morte, mas há a triagem pelo sucesso ou falha de atos especiais - a contraparte, eu suponho, da assim chamada seleção fisiológica (DEWEY, 1972, p. 50).
\end{abstract}

Note-se o papel atribuído ao conceito de indivíduo, como portador de funções que são selecionadas. O meio ambiente social, por meio das variações introduzidas pelas ações individuais, é moldado pela seleção, e como efeito de tal mecanismo, este meio ambiente ampliase e cresce em complexidade, mas sem tender a nenhum tipo de fim predeterminado.

\title{
5 EVOLUÇÃO E O QUE SE DEVE FAZER
}

Alguém poderia, a esta altura, objetar que Dewey não trata de ética, apenas de evolução e comportamento animal, instintivo ou deliberado. Não há discussão sobre o que é certo fazer e por que. Não há uma argumentação a favor de princípios ou normas, ou finalidades, que possa orientar a formulação de juízos de valor. Uma versão desta objeção seria a de que Dewey discute questões de fato e não questões de valor. Estaria cometendo, portanto, o equívoco conhecido como falácia naturalista.

De certo modo é verdade que Dewey não está debatendo problemas éticos do modo como vinha fazendo a filosofia tradicional. Ele discute a condição de possibilidade dos problemas éticos, num olhar que vai aos seus fundamentos. Impulsos e instintos, hábitos, metas e fins conscientes, instituições; estes são os ingredientes da receita de Dewey, na segunda parte de seu argumento quando, tendo respondido suficientemente a Huxley, passa a desenvolver de modo mais original sua própria tese.

Haveria, portanto, um sentido em que Dewey está realmente tratando de ética. Os impulsos naturais se reconstroem na forma de hábitos, como funções comportamentais que ocasionam uma melhor adaptação ao ambiente social, no qual as ações dos outros indivíduos desempenham papel fundamental. O grande princípio moral, o valor e finalidade maior da ação ética, consistiria em desenvolver instituições públicas e hábitos individuais que permitam o ajustamento de seus participantes e portadores ao ambiente em constante mudança, sem recair na 
obsolescência e sem gerar conflitos que impeçam atingir as metas que os indivíduos perseguem. Conforme Dewey: “Ainda, se os hábitos tornam-se tão fixos que não podem ser adaptados aos fins sugeridos por novas situações, eles são barreiras à conduta e inimigos da vida" (DEWEY, 1972, p. 48). A reflexão de Dewey manifesta o que se poderia chamar de uma intenção normativa, bem diferente de uma intenção meramente descritiva das condutas componentes da ética.

A propósito da alegação de normatividade, pode-se encontrar uma análise precisa e bem articulada acerca da discussão entre Huxley e Dewey no trabalho de John Teehan. Seu artigo intitulado "Evolution and Ethics: The Huxley/Dewey Exchange" (TEEHAN, 2002), empreende um exame muito perspicaz do assunto aqui abordado. Teehan reconhece o aspecto normativo implicado na ética evolucionista: Em perfeito acordo com Dewey, admite que a reflexão acerca do desenvolvimento das distinções morais, na relação dinâmica dos agentes em seu ambiente social, é uma reflexão que afeta os próprios julgamentos morais que são emitidos pelos agentes nas diversas ocasiões. Entretanto, é possível acrescentar um ponto importante às suas conclusões.

Este comentador argumenta acerca da viabilidade do projeto de uma ética evolutiva. Refere-se à adequação do método científico como ferramenta de estudo das questões relativas à ética, sobretudo no que toca às transformações ocorridas no mundo dos valores e condutas, em resposta às mudanças no ambiente social. Ele aponta para a tese de Dewey em "Evolução e ética" como uma das primeiras contribuições a este debate. Segundo ele:

\footnotetext{
A ética é concernente à avaliação de normas, valores e comportamentos em termos de sua funcionalidade na perseguição de certos fins. Ela é uma disciplina pragmática. Portanto, perguntar sobre a validade moral de uma norma, valor ou comportamento particular é perguntar como esta coisa funciona sob certas condições (TEEHAN, 2002, p. 235).
}

O caso é que Teehan parece recusar a possibilidade de que a ética evolutiva, tal como Dewey a concebe, possa indicar valores e princípios de abrangência mais geral.

Assim, ao argumentar contra a eleição de valores últimos, parece recair em um relativismo da ética, que está aparentemente em desacordo com o ponto de vista deweyano. Teehan desenvolve seu parecer baseando-se na recusa de Dewey em submeter a filosofia a definições e conceitos de caráter abstrato, fixo e transcendente. Assim, julga estar sendo rigoroso em sua compreensão de Dewey, ao afirmar que “a questão ética que concerne a nós não é esta da 
validade última, mas sim aquela com conseqüências concretas, práticas, para o modo no qual as pessoas vivem suas vidas" (TEEHAN, 2002, p. 237). Se esta afirmação for interpretada no sentido de uma recusa à admissão de uma normativa independente do processo natural e social da moralidade, se for uma recusa em recair na oposição entre evolução e ética, como queria Huxley, então é preciso concordar inteiramente com Teehan. Pois deve ter ficado claro que Dewey mantém sua posição naturalista evolutiva, conforme tem sido defendido, nos temas da ética.

Acontece que esta afirmação acima citada, assim como a de que "nós não precisamos de uma definição do que é bom; precisamos saber como agir de modo a tornar as coisas melhores" (TEEHAN, 2002, p. 237), pode significar algo mais do que uma chamada de atenção para a aplicação do que Dewey vinha chamando de "método evolutivo" à ética. Se a posição de Teehan implica em que não há uma escala de valores em que algum seja o valor mais primordial, se sua posição implica uma recusa da admissão de um valor que seja o fundamento da normativa que se aplica às condutas particulares, então é preciso discordar de sua compreensão, a fim de manter a integridade da leitura que se faz da filosofia de Dewey. Pois, assim como no artigo "Evolução e Ética", em outras passagens de sua obra o autor recorre à generalização, a princípios de maior abrangência, como formas de orientar o pensamento e propor explicações e justificativas.

A ética de Dewey, é preciso acentuar, é uma ética evolutiva, naturalista, adepta da aplicação do pensamento experimental para a discussão dos julgamentos e valores. Mas nem por isso é uma ética relativista, que rejeita a aplicação de princípios e fundamentos gerais. Falando mais claramente: nós precisamos, de fato, de uma definição do que é bom. É preciso que o esforço da investigação das situações e eventos particulares conduza à inferência de princípios de validade geral. Teehan parece tender a uma leitura que vê a ética de Dewey como uma ética situacional, e com isso, dá muita importância aos fatos particulares, descuidando de que uma parte crucial da ética refere-se não a fatos mas a valores e princípios. O caso é que tais princípios não emanam, como queria Huxley e os pensadores da tradição, da intuição ou descoberta de valores imutáveis ou transcendentes.

\section{O PENSAMENTO EVOLUTIVO E O VALOR SUPREMO}

No seu artigo de 1902, intitulado “The Evolutionary Method as Applied to Morality", Dewey dá continuidade a sua reflexão sobre a ética, desta vez propondo as diretrizes de sua 
consideração segundo o método científico. Ele afirma logo no início de seu discurso: "Muitos escritores mantém que discutir a mente ou a moralidade em termos da série histórica é evidenciar tal ignorância das distinções filosóficas mais rudimentares assim como alegar total inaptidão para a tarefa assumida" (DEWEY, 1902, p. 108). Será que entre estes "muitos escritores" poder-se-ia incluir Huxley? Talvez Dewey não estivesse pensando especialmente em Huxley ao fazer tal caracterização, mas sim nos filósofos abstratos, de tendência mais dualista. Em todo o caso, sua resposta pode servir também como resposta a Huxley, na medida em que este último defende a oposição entre o processo ético e o processo evolutivo. Desta distinção dos dois processos decorre inevitavelmente uma distinção nos discursos e nos métodos de investigação de cada um destes processos.

Dewey, conforme se sabe, discorda desta dissociação, e por isso, a aplicação proposta por ele do método histórico figura como um meio termo entre duas atitudes extremas que ele identifica respectivamente com a "falácia materialista" e a falácia do "idealismo". Ambas estão relacionadas diretamente com a idéia de causa-e-efeito, segundo a qual um evento antecedente é suposto estar em certa relação lógica com seu conseqüente, a ponto de o antecedente ser considerado a causa e o consequente o efeito. A compreensão obtida mediante a inferência causal exige uma consciência da temporalidade, de um processo em andamento, e por isso Dewey denomina de "método evolutivo" ao método de investigação que aborda um fenômeno como parte integrante de uma série de mudanças.

Tendo isso em mente, o materialista seria aquele que atribui superioridade e maior ênfase ao antecedente. Segundo o materialista, seria mais importante conhecer os estágios anteriores do processo, a partir dos quais todo o resto poderia ser deduzido. Dewey afirma que o que está envolvido na adoção da falácia materialista, na visão de Dewey, é uma "concepção metafísica da causalidade" (DEWEY, 1902, p. 116). É como se a relação causal fosse algo que reside de algum modo nas próprias coisas e não apenas no conhecimento que se tem delas. Então, compreender os estágios iniciais de um processo levaria o investigador a possuir a chave de que decorre a compreensão de todo o processo.

O idealista, por sua vez, seria aquele que atribui superioridade e maior ênfase ao conseqüente, pois ele seria a atualização, a realização manifesta de uma latência, de uma tendência, de uma potência que se escondia nos estágios anteriores. Como se todos os estágios do processo fossem somente preparação para um fim pré-determinado. Dewey espera superar, em 
assuntos relacionados à ética e à conduta moral, estas duas falácias - o materialismo e o idealismo - ao empregar o método evolutivo, para o qual tanto os antecedentes como os conseqüentes são manifestações de um processo em contínua mudança.

A noção manifesta de continuidade da experiência em um curso constante é um freqüente recurso do autor para superar as distinções e pares de opostos de que a filosofia tradicional está carregada. Para ele é importante ao pesquisador da ética tentar reconstruir o processo contínuo no qual diferentes estágios de desenvolvimento da moralidade tiveram lugar, como partes que só se distinguem na abstração do pesquisador.

Não foi apenas através de estudos em fisiologia, de que Dewey fala em "From Absolutism to Experimentalism", mas no esforço intelectual de representar a ética em um viés integralmente evolutivo que o debate com Thomas Huxley teve efeito decisivo no pensamento deweyano. Dewey não recai em nenhuma espécie de relativismo ético com sua abordagem evolutiva. Ele nos fala da necessidade de manter as instituições que chegaram até nós, enquanto reproduzimos estas instituições de modo a que elas nos sirvam sob condições em mudança. Desistir das instituições é o caos e a anarquia; manter as instituições inalteradas é morte e fossilização (DEWEY, 1972, p. 48). O que ele quer dizer é que o entendimento da vida associada como parte de um processo evolutivo, leva a admitir invariavelmente este próprio processo evolutivo - na forma do crescimento e continuidade da experiência - como o objetivo da ação ética.

A inteligência veio a existir em um mundo onde não havia inteligência, por um processo evolutivo de modificação e seleção acumulativa de funções mantidas pelos seres vivos. Do mesmo modo, e em total coerência com esta posição, os valorese condutas componentes da esfera ética também vieram a existir em um mundo onde não havia ética, não havia direitos, não havia valores conscientes. A ética veio a existir pelo mesmo processo natural identificado por Dewey como atuando nos ambientes sociais de ontem e de hoje.

Estudos recentes da obra de Dewey, que intentam compreender o sentido de seu pensamento nos contextos atuais, manifestam uma leitura semelhante a esta que se propõe. É o caso, por exemplo, de Jim Garrison no capítulo de abertura da obra Reconstructing Democracy, Recontextualizing Dewey (2008). Ele aponta a continuidade inextricável entre o processo natural e o processo ético, e suas consequências para a reflexão acerca dos valores. Segundo ele:

Ainda que Dewey não pensasse que os direitos humanos e semelhantes fossem inatos, ele pensava que eram tremandas aquisições culturais, partes de nosso contexto 
contemporâneo, que não deviam ser apenas preservados, mas expandidos. Liberdade, direitos e inteligência são aquisições culturais e individuais para Dewey, e não dons naturais (GARRISON, 2008, p. 3).

O que a investigação evolutiva dos valores e normas revela, é não só a origem da ética a partir de instintos e impulsos mais primitivos a partir dos quais ela emerge por seleção acumulativa. Mais que isso, a ética mantém-se como um instrumento, como um conjunto de funções de altíssimo valor adapativo, na medida em que preservam e asseguram a continuidade deste processo de crescimento e de desenvolvimento, no ambiente complexo das sociedades humanas.

A reflexão ética aponta para o crescimento e a reconstrução adaptativa de todas aquelas condutas, valores e normas que assegurem a continuidade da vida social e seu desenvolvimento nos ambientes em mudança com os quais esta vida interage. É neste sentido que se propõe aqui apreender o sentido da lição de Dewey. Na medida em que as condições mudaram, o ambiente é indefinidamente mais complexo, mais amplo, e mais variável, assim, por necessidade e como uma questão biológica e cósmica, não meramente ética, as funções selecionadas diferem (DEWEY, 1972, p. 53). O crescimento para novos ambientes já aparece em "Evolução e Ética" como um sentido evolutivo, a ser assumido como valor maior a ser perseguido nas iniciativas individuais e coletivas.

Então, a ética deweyana não é apenas uma reflexão situacional, ou relativa. Ela é a busca de um nexo, de um sentido da conduta moral que, mesmo sendo inferido e justificado pelas circunstâncias particulares, remete a uma regularidade mais ampla. Mais ampla até do que a experiência humana consciente, indo encontrar seu alicerce final no processo cósmico de evolução, cujo mecanismo operante é o da seleção natural. Diz ele:

\footnotetext{
Nós sabemos que através do que chamamos de opinião pública e educação certas formas de ação são constantemente estimuladas e encorajadas, enquanto outros tipos são constantemente objetados, reprimidos e punidos. Que diferença existe em princípio entre esta mediação dos atos do indivíduo pela sociedade e o que é ordinariamente chamado de seleção natural, eu sou incapaz de ver (DEWEY, 1972, p. 50).
}

Assim, a normativa resultante da reflexão ética bem conduzida, precisa atender ao critério de favorecer os seus portadores na busca por formas mais adaptadas de conduta.

Por isso, este momento em que percebemos que o processo cósmico (natural) e o ético fazem parte, para Dewey, da mesma ordem de fenômenos é "quando se descobre que o homem 
em suas lutas conscientes, em suas dúvidas, tentações e derrotas, em suas aspirações e sucessos, é movido e mantido na superfície pelas forças que desenvolveram a natureza" (DEWEY, 1972, p. 53). O que instaura a eticidade não é o fim da seleção natural, entendida como fundamento do processo cósmico. O que instaura a eticidade é a passagem da conduta guiada pela variação cega, para a previsão e consciente estabelecimento de meios e fins socialmente compartilhados. Persiste a demanda por adaptação dinâmica ao ambiente, acrescida das complexidades inerentes ao ambiente social, acentuada pela mudança constante e acelerada da cultura, que exige dos hábitos, crenças e valores a capacidade de sobreviverem a um processo de seleção.

\section{CONSIDERAÇÕES FINAIS}

É possível fazer a leitura desta filosofia considerando que o ser humano, para Dewey, é pensado como parte do mundo natural. O peso dado à intencionalidade individual, à subjetividade humana, constituída como condição do processo ético, é reduzido à posição de um resultado, e nem sequer de um resultado definitivo. Uma vez que o ambiente em que o ser humano se encontra está em constante transformação, os elementos constituintes da própria subjetividade também estão.

Temos então, como elementos desta concepção ética, os seguintes:

1. Adaptação dinâmica entre o organismo e o meio.

2. Seleção em sentido amplo, incluindo seleção não só de variações biológicas, mas de variações resultantes da mentalidade, como valores, crenças e instituições.

3. Luta pela existência contra obstáculos e impedimentos diversos, mas que envolve cooperação e ajustamentos entre os indivíduos. Isto implica a atribuição de um papel fundamental à comunicação.

Aquilo que, posteriormente, o autor iria desenvolver na forma de uma defesa do modo de vida democrático e do valor absoluto do crescimento está, já neste artigo de juventude aqui discutido, presente em sua consideração da relação de continuidade entre evolução e ética. Os valores do crescimento e da democracia são valores últimos, resultantes de uma consideração de que tipo de vida é desejável e valiosa, dado o tipo de mundo em que os agentes se encontram. A democracia, ao ser descrita por Dewey em obras posteriores como um modo de vida associado é, na verdade, o termo que reúne sob seu escopo os componentes de uma ética resultante de uma 
visão naturalista e evolutiva, no caminho aberto pelas questões tratadas por Dewey quando metaforicamente falando - relata sua visita ao jardim de Huxley. 


\section{REFERÊNCIAS}

DEWEY, John. (1898). "Evolution and Ethics". In: The Early Works of John Dewey 1882-1898, Vol. 5 (1895-1898). Jo An Boydston (Ed.). Carbondale \& Edwardsville: Southern Illinois University Press. 1972.

Review, Vol. XI, n. 2, pp. 107-124. 1902.

. "The evolutionary method as applied to morality". In: The Philosophical .(1909). The Influence of Darwinism on Philosophy. In: The Influence of Darwin on Philosophy, and Other Essays in Contemporary Thought. New York: Holt, 1910; London: Bell, 1910.

1959.

. (1916). Democracia e Educação. São Paulo: Companhia Editora Nacional.

(1930). "From Absolutism to Experimentalism". In: The Philosophy of John Dewey. Chicago: Chicago University Press. 1981.

GARRISON, Jim. "Reconstructing Democracy and Recontextualizing Deweyan Pragmatism". In: Reconstructing Democracy, Recontextualizing Dewey. New York: State University of New York Press. 2008.

HUXLEY, Thomas Henry. Collected Essays. Vol. 9. Evolution and Ethics and other Essays. London: Elibron Classics. 2001.

TEEHAN, John. "Evolution and Ethics: The Huxley/Dewey Exchange". In: The Journal of Speculative Philosophy. Vol. 16, n. 13, pp. 225-238. 2002. 